\title{
Abnormal Antithrombin III with Defective Serine Protease Binding (Antithrombin III “Denver”)
}

James E. Sambrano, Linda J. Jacobson, E. Basil Reeve, Marilyn J. Manco-Johnson, and Wm. E. Hathaway

Departments of Pediatrics and Medicine, University of Colorado School of Medicine, Denver, Colorado 80262

\begin{abstract}
A hereditary (three family members) deficiency of antithrombin III (AT-III) in which AT-III antigen (AT-III ag) is normal in spite of low heparin cofactor and antithrombin activity is described. Plasma levels were: AT-III ag, 0.92-0.96 U/ml; ATIII heparin cofactor activity, 0.54-0.62 $\mathrm{U} / \mathrm{ml}$; progressive antithrombin activity index, 0.13-0.18; anti-Xa activity, 0.50-0.56 $\mathrm{U} / \mathrm{ml}$. Plasma crossed immunoelectrophoresis (CIE) patterns performed with and without added heparin were normal, but serum CIE revealed a decreased complex peak. Purification of the patient's plasma AT-III by heparin-sepharose affinity chromatography showed a normal protein recovery and elution profile, but the purified AT-III fraction showed only $50 \%$ of the normal progressive thrombin neutralization and anti-Xa activity. When thrombin-antithrombin (TAT) complexes were formed by incubating with excess thrombin, SDS-polyacrylamide gel electrophoresis (PAGE) analysis revealed that half the patient ATIII formed TAT complexes while the remainder migrated as free AT-III. All the control AT-III formed TAT complexes. The patient's nonreacting AT-III (AT-III "Denver"), isolated by affinity chromatography, showed CIE and SDS-PAGE migration patterns characteristic of normal AT-III but failed to bind thrombin or Xa. Calculations from turnover studies in one patient and normal subjects with autologous ${ }^{131}$ I-AT-III suggested that ATIII "Denver" is removed from the plasma slightly more rapidly than normal.

These studies indicate that the patients' variant AT-III molecule was characterized by normal heparin interaction but defective binding and inhibition of thrombin and Xa. These characteristics allow isolation of the nonreactive variant molecule by heparin-sepharose affinity chromatography.
\end{abstract}

\section{Introduction}

Antithrombin III (AT-III) ${ }^{1}$ has been characterized as the principal physiologic inhibitor of serine proteases generated by the coagulation system $(1,2)$. Hereditary AT-III deficiency states have

This study was presented in part at the meeting of the American Society of Hematology, San Francisco, CA, December 1983.

Address reprint requests to Dr. Hathaway, Department of Pediatrics, University of Colorado School of Medicine, 4200 East Ninth Avenue (C-220), Denver, CO 80262.

Received for publication 26 August 1985.

1. Abbreviations used in this paper: AT, antithrombin activity; AT-III, antithrombin III; $\mathrm{AT}_{\mathrm{D}}$, variant antithrombin III levels; CIE, crossed immunoelectrophoresis; PAGE, polyacrylamide gel electrophoresis; RIE, rocket immunoelectrophoresis; TAT, thrombin-antithrombin.

J. Clin. Invest.

(C) The American Society for Clinical Investigation, Inc. 0021-9738/86/03/0887/07 \$1.00

Volume 77, March 1986, 887-893 been recognized with increasing frequency since the first heritable quantitative deficiency state was described in 1965 (3) and the first qualitative deficiency state in 1974 (4). We have recently evaluated a family with a qualitative AT-III deficiency characterized by abnormal serine protease interaction. By exploiting the thrombin binding defect, the variant AT-III was isolated, studied, and tentatively designated AT-III "Denver." Biochemical and turnover studies are presented here.

\section{Methods}

Sample collection, coagulation studies, and anticoagulant assays. Routine blood samples were obtained by the standard two-syringe technique with $9 \mathrm{vol}$ of blood mixed into $1 \mathrm{vol}$ of citrate anticoagulant $(3 \mathrm{vol} 0.1 \mathrm{~mol} /$ liter trisodium citrate to $2 \mathrm{vol} 0.1 \mathrm{~mol} /$ liter citric acid). Plasma was separated by centrifugation at $1,400 \mathrm{~g}$ for 30 minutes. On several occasions, one affected family member ( $\mathrm{AH} \mathrm{Jr}$ ) donated plasma units by routine manual plasmapheresis methods. Whole blood was collected into commercially prepared bags containing citrate anticoagulant (Fenwal Laboratories, Div. of Travenol Laboratories, Inc., Deerfield, IL). After each individual unit of blood was collected, plasma was separated by bag centrifugation and manually expressed into a second collecting bag. The red cells were then returned to the patient. The plasma was centrifuged again at $25,000 \mathrm{~g}$ for $30 \mathrm{~min}$, divided into aliquots and stored at $-70^{\circ} \mathrm{C}$ until further testing.

Prothrombin time, partial thromboplastin time, thrombin time, fibrinogen, fibrin split products, fibrin monomer, and euglobulin lysis time were measured by standard laboratory methods (5). Rocket immunoelectrophoresis (RIE) using commercial antisera (CalbiochemBehring Corp., La Jolla, CA) was employed to measure $\alpha_{2}$-macroglobulin and $\alpha_{1}$-antitrypsin (Kallestad Laboratories, Inc., Austin, TX). Protein C measurements were performed by Dr. Richard Marlar (Blood Center of Southeastern Wisconsin, Milwaukee).

Estimates of AT-III antigen were obtained by RIE using our own or commercial (Behring Diagnostics, American Hoechst Corp., San Diego, CA) rabbit antisera; AT-III activity, AT, was measured by heparin cofactor activity (6). Both were standardized against the same plasma pool from 30 normal adult subjects. Variant AT-III levels, $\mathrm{AT}_{\mathrm{D}}$, were obtained by difference. In studies on plasma from eight healthy controls, the mean RIE was $101 \%$, SD $9.1 \%$, and the mean heparin cofactor activity was $100.5 \%$, SD 9.4\%, while the mean percentage of RIE minus heparin cofactor activity was $0.5 \%$, SD $3.4 \%$, indicating $\mathrm{AT}_{\mathrm{D}}$ could be measured within 6-7\%. Progressive antithrombin activity was measured in a system employing heat-defibrinated plasma incubated with a known amount of bovine thrombin, and the results were recorded in seconds measuring the time to clot formation after the addition of the incubation mixture to fibrinogen (7). Simultaneous controls were performed. An index of progressive antithrombin activity was calculated employing the results obtained from the patient's plasma divided by the results from the simultaneously run control plasma. Known heterozygotes for AT-III deficiency display an activity index of 0.17-0.29 with this method (7). Anti-Xa activity was measured by a previously described technique (8). After the purification of AT-III from patient and control plasmas, this material was tested for its antithrombin and anti-Xa activity. Equimolar amounts of purified AT-III and a protease substrate (human thrombin or Xa) were incubated with or without heparin. Aliquots of the reaction mixture were withdrawn at specified times and residual protease activity was measured immediately by chromogenic substrate analysis. These 
data were plotted on a graph displaying percent residual protease activity versus incubation time. Crossed immunoelectrophoresis (CIE) analysis with and without heparin $(17 \mathrm{U} / \mathrm{ml})$ added to the agarose in the first dimension was performed on plasma and serum samples by methods previously described (9).

AT-III isolation by affinity chromatography. AT-III was purified by modifications of previously described techniques $(10,11) .40 \mathrm{ml}$ of fresh, heat-defibrinated, citrated plasma $(9 \mathrm{vol}$ blood, $1 \mathrm{vol} 0.12 \mathrm{~mol} / \mathrm{liter}$ trisodium citrate) was diluted $1: 1$ with Tris-citrate- $\mathrm{NaCl}$ buffer $(0.01 \mathrm{~mol} /$ liter Tris, $0.01 \mathrm{~mol} /$ liter citrate, $0.145 \mathrm{~mol} /$ liter $\mathrm{NaCl}, \mathrm{pH} 7.5$; buffer A) and slowly applied to an 8-ml column of heparin-sepharose prepared as described by Damus and Rosenberg (10). The loaded column was washed sequentially with $5 \mathrm{vol}$ of buffer A followed by 5 vol of buffer B (buffer A without citrate). After a wash with $5 \mathrm{vol}$ of buffer $\mathrm{C}(0.01 \mathrm{~mol} / \mathrm{liter}$ Tris, pH 7.5, $0.5 \mathrm{~mol} / \mathrm{liter} \mathrm{NaCl}$ ), a linear salt gradient was applied. The fractions were measured for $\mathrm{OD}_{280}, \mathrm{AT}-\mathrm{III}$ antigen, and heparin cofactor activity and the antigen-positive fractions were pooled, diluted to $\sim 0.3$ $\mathrm{mol} /$ liter $\mathrm{NaCl}$ by the addition of appropriate amounts of buffer $\mathrm{B}$. This solution was then applied onto a 4-ml heparin-Sepharose column which was washed with 10 vol of buffer $B$ and then eluted with buffer $D(0.06$ $\mathrm{mol} /$ liter $\mathrm{NaCl}, 0.01 \mathrm{~mol} / \mathrm{liter} \mathrm{Tris}, \mathrm{pH} 8.4$ ). This yielded a homogeneous AT-III preparation as demonstrated by SDS-polyacrylamide gel electrophoresis (SDS-PAGE) (12). Previously performed elutions by this technique had been shown to clear the column of essentially all AT-III antigenpositive material.

Studies of radioiodinated variant AT-III. For radioiodination, fresh plasma AT-III was purified by heparin-Sepharose chromatography. The labeling of normal and patients' plasma ${ }^{131}$ I-AT-III and calculation of AT-III turnover rate were performed by methods previously described (13).

Thrombin-antithrombin (TAT) complex formation. AT-III in buffer $D$ purified as described above from patients, controls, and isolated variant AT-III (see below) was incubated with human thrombin (lot $\mathrm{H} 2$, Bureau of Biologics, Food and Drug Administration, Bethesda, MD) diluted to $200 \mathrm{U} / \mathrm{ml}$ with distilled water for $1 \mathrm{~h}$ at $37^{\circ} \mathrm{C}$ in plastic tubes. After dialysis to remove Tris, reaction ingredients were analyzed by SDS-PAGE.

Isolation of variant AT-III from TAT mixtures. TAT complexes were formed by mixing buffered (buffer D) solutions of purified AT-III from patients and controls with human thrombin $(180 \mathrm{U} / \mathrm{ml}$ in distilled water) in proportions that had been determined in prior mixing experiments. For control AT-III, the amount of thrombin added was sufficient to neutralize approximately one-half of the measured heparin-cofactor activity. For the patient's AT-III solution, thrombin was added in an amount which yielded no measurable heparin cofactor activity and a trace residual amount of thrombin. The mixture of the AT-III and thrombin solutions was incubated for $1 \mathrm{~h}$ at $37^{\circ} \mathrm{C}$ in plastic tubes. The reaction mixtures were then diluted 1:5 with buffer adjusted to a final $\mathrm{NaCl}$ concentration of $0.2 \mathrm{~mol} / \mathrm{liter}, \mathrm{pH}$ 7.5. This solution was loaded onto a 4-ml heparinsepharose column. The column was washed with $10 \mathrm{vol}$ of buffer followed by a stepwise elution process. Each eluting solution contained equivalent concentration of Tris $(0.01 \mathrm{~mol} /$ liter $)$ but sequentially increasing concentrations of $\mathrm{NaCl}(0.01 \mathrm{~mol} / \mathrm{liter}, \mathrm{pH} 7.5 ; 0.05 \mathrm{~mol} / \mathrm{liter}, \mathrm{pH} 7.5 ; 0.6$ $\mathrm{mol} /$ liter, $\mathrm{pH} 8.4$, respectively). 5 vol of each eluting solution were added to the column in sequence. Eluates were collected in aliquots from the washing and elution steps. Individual aliquots were analyzed for $\mathrm{OD}_{280}$, AT-III antigen, and heparin cofactor activity. Representative samples from each step were tested by SDS-PAGE and CIE.

\section{Case report}

AH is a 16-yr-old black female who presented with the signs and symptoms of an acute lower-extremity deep-vein thrombosis occurring spontaneously 2 mo after initiation of oral contraceptives. Routine coagulation studies performed at the time of the acute episode including AT-III antigen level were reported to be within normal limits. Therapy was initiated with systemic heparin anticoagulation with resolution of the acute episode, and she was maintained on warfarin therapy for $4 \mathrm{mo}$. She was referred to our clinic for further evaluation $1 \mathrm{mo}$ after discontinuation of warfarin.

The patient's history and the family history were negative for addi- tional thromboembolic phenomena. The patient and all six members of her immediate family were tested, and a qualitative deficiency of ATIII was documented in three of seven family members. The patient subsequently suffered a recurrence of deep-vein thrombosis in the first trimester of a pregnancy which eventually terminated in the spontaneous delivery of a previable 22-wk-old fetus. Management of a subsequent pregnancy included administration of subcutaneous heparin and intrapartum AT-III concentrate (details to be reported elsewhere).

\section{Results}

A qualitative deficiency of AT-III was documented in three of seven family members in two generations (Fig. 1). Representative values for AT-III antigen and activity assays for family members are shown in Table I. While all members of the family demonstrate normal antigen levels, $\mathrm{AH}$, her father ( $\mathrm{AH} \mathrm{Sr}$ ), and her brother (AH Jr) show a partial AT-III deficiency documented in both heparin cofactor and progressive antithrombin activity assays. When the AT-III cofactor assay was done without heparin, the antithrombin activity was $54 \%(\mathrm{AH})$ and $60 \%(\mathrm{AH} \mathrm{Jr})$ of normal. For all family members, routine coagulation tests, assays for fibrinolytic activity, as well as $\alpha_{2}$-macroglobulin, $\alpha_{1}$-antitrypsin, and protein $C$ levels were within normal limits (data not shown).

CIE performed on plasma and serum samples revealed patterns as represented in Fig. 2. In the example shown, heparin was present in the agarose first dimension. Both patient and control plasmas demonstrate identical migration distance and pattern. In serum samples, however, a difference is noted. Two distinct peaks are seen in the control serum: a broad-based, slowly migrating peak of AT-III-serine protease complexes and a more rapidly migrating peak of uncomplexed AT-III. In the patient's serum the AT-III complex peak is much reduced, suggesting either decreased or unstable complex formation. CIE performed without heparin (not shown) revealed patterns essentially unchanged from those shown in Fig. 2.

The data generated during the timed neutralization of thrombin and Xa by AT-III purified from normal and patient plasma are shown in Figs. 3 and 4. The progressive neutralization of either protease substrate by AT-III is demonstrated as well as the acceleration of the process in the presence of heparin, but purified patient AT-III only neutralized $50-70 \%$ of the thrombin and $\mathrm{Xa}$ neutralized by purified normal AT-III.

$T A T$ complex analysis by SDS-PAGE. Mixtures of purified AT-III and thrombin resulted in the formation of TAT complexes. The reactants and their products were evaluated by SDSPAGE as shown in Fig. 5. Bands representing control AT-III, patient AT-III, and thrombin are shown in lanes $A, B$, and $C$, respectively. Lanes $D$ and $E$ show the results of mixing equimolar amounts of control AT-III $(D)$ or patient AT-III $(E)$ with throm-

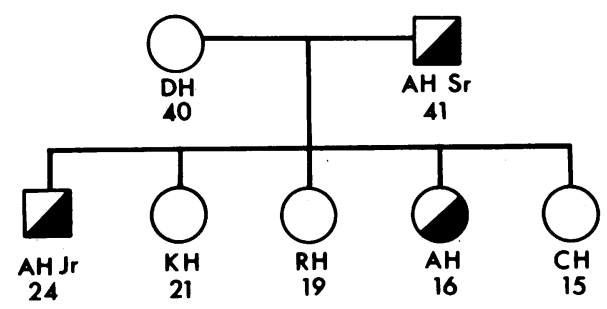

Figure 1. Pedigree of immediate family members of proband $\mathrm{AH}$ with ages shown. AH, her father, $\mathrm{AH} \mathrm{Sr}$, and sibling, $\mathrm{AH} \mathrm{Jr}$, are heterozygotes for AT-III "Denver." 
Table I. Values for AT-III Measurements for Each Family Member

\begin{tabular}{|c|c|c|c|}
\hline Subject & $\begin{array}{l}\text { AT-III antigen } \\
(\mathrm{N}=0.71-1.19 \mathrm{U} / \mathrm{ml})\end{array}$ & $\begin{array}{l}\text { AT-III heparin } \\
\text { cofactor activity } \\
(\mathrm{N}=0.80-1.23 \mathrm{U} / \mathrm{ml})\end{array}$ & $\begin{array}{l}\text { Progressive } \\
\text { antithrombin } \\
\text { activity index } \\
(\mathrm{N}=0.66-1.38)\end{array}$ \\
\hline${ }^{*} \mathrm{AH}$ & 0.92 & 0.54 & 0.18 \\
\hline $\mathrm{AH} \mathrm{Sr}$ & 0.92 & 0.62 & 0.13 \\
\hline $\mathrm{AH} \mathrm{Jr}$ & $0.96(0.04) \S$ & $0.57(0.08) \S$ & 0.16 \\
\hline $\mathrm{DH}$ & 0.86 & 0.98 & 0.70 \\
\hline$\ddagger \mathrm{KH}$ & 0.80 & 0.88 & 0.26 \\
\hline RH & 1.00 & 1.07 & 0.76 \\
\hline $\mathrm{CH}$ & 1.18 & 0.83 & 0.66 \\
\hline
\end{tabular}

Progressive antithrombin activity index is ratio of patient/control clotting times (see text for details of method). N, normal.

* Proband.

‡ Studies while taking oral contraceptives.

$\S$ Mean and standard deviation of four studies.

bin. Lane $D$ shows only a slowly migrating band representing TAT. Lane $E$ shows TAT complexes, residual unbound thrombin, and free AT-III. Lane $F$ shows that when twice the molar concentration of patient AT-III is incubated with thrombin, the thrombin band disappears and approximately equimolar bands of TAT complexes and uncomplexed AT-III appear. The residual free AT-III suggests the presence of AT-III species that fail to react with thrombin. In addition, SDS-PAGE gels of a mixture of isolated variant AT-III (see below) and thrombin did not show any TAT complexes (not shown).

Isolation of the variant AT-III molecule. The above studies suggest that the patient's AT-III consists of roughly equal proportions of normal AT-III and a variant species characterized
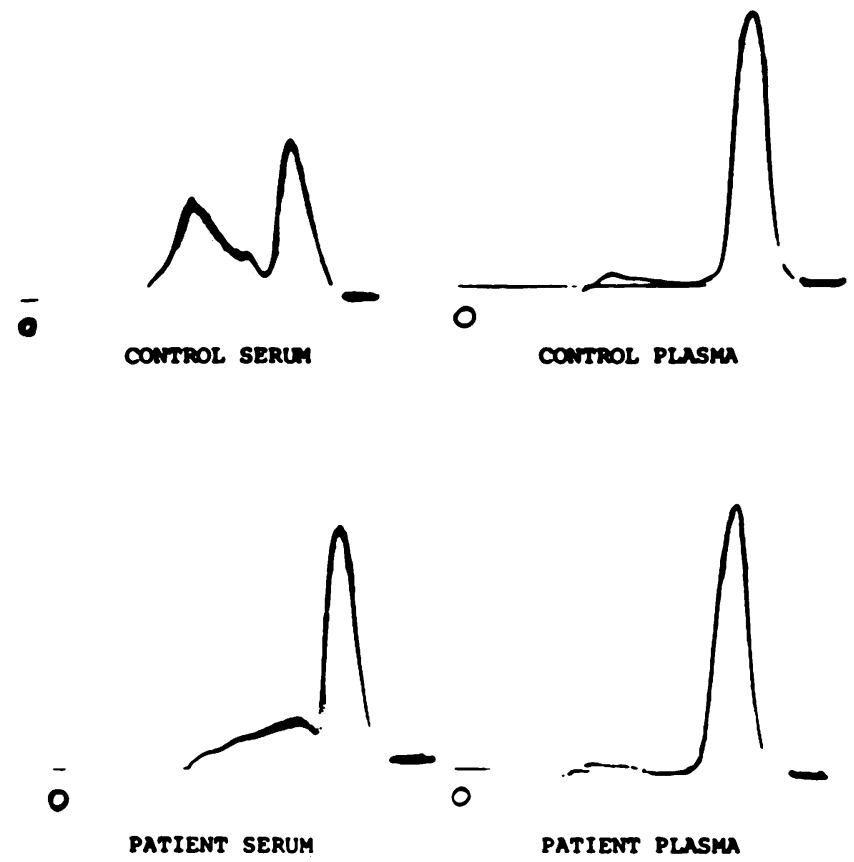

Figure 2. CIE patterns of control and patient samples of serum and plasma. Heparin $(17 \mathrm{U} / \mathrm{ml})$ present in agarose in first dimension.

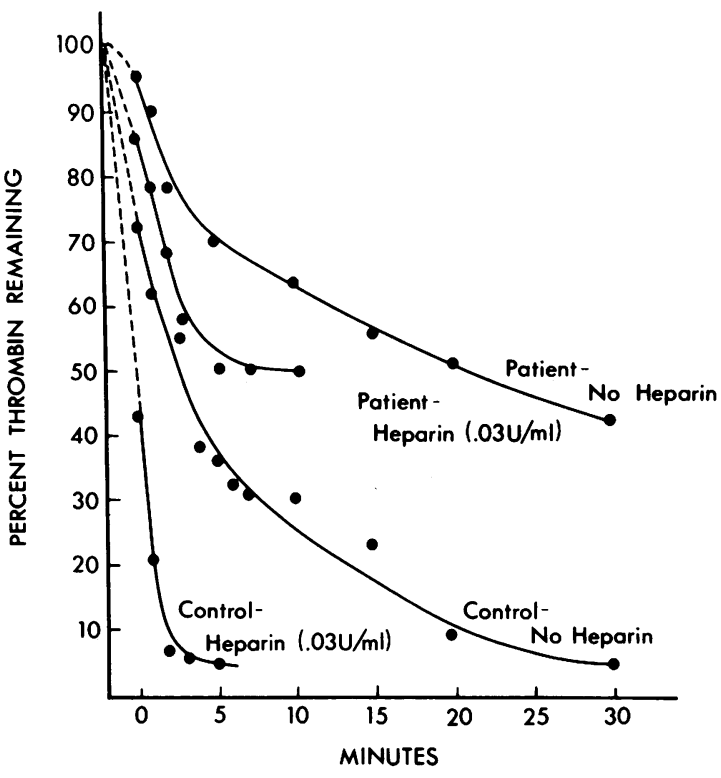

Figure 3. The neutralization (incubation of mixture at $37^{\circ} \mathrm{C}$ ) of thrombin activity by purified preparations of AT-III in the presence and absence of heparin. The AT-III was prepared by heparin-sepharose affinity chromatography from the subjects' plasma. Patient AT-III (AT-III "Denver" plus normal AT-III) shows a decreased rate of thrombin neutralization as compared to control (all normal AT-III).

by normal heparin affinity but diminished or absent binding to thrombin and $\mathrm{Xa}$. To test this hypothesis, additional affinity chromatographic studies were performed. Equimolar mixtures of AT-III and thrombin were made and loaded onto heparinsepharose columns. These were then eluted by increasing increments of salt concentration ("stepwise") and the material eluted by each increment was analyzed for AT-III antigen and heparin cofactor activity. The profiles of two such elution analyses are shown in Fig. 6. The material eluted at the low $(0.3 \mathrm{~mol} \mathrm{NaCl})$ and intermediate $(0.5 \mathrm{~mol} \mathrm{NaCl})$ salt concentrations for both patient and control was antigen-positive and heparin cofactor activity-negative. SDS-PAGE analysis (not shown) of the pooled material from both of these elution steps reveals primarily TAT

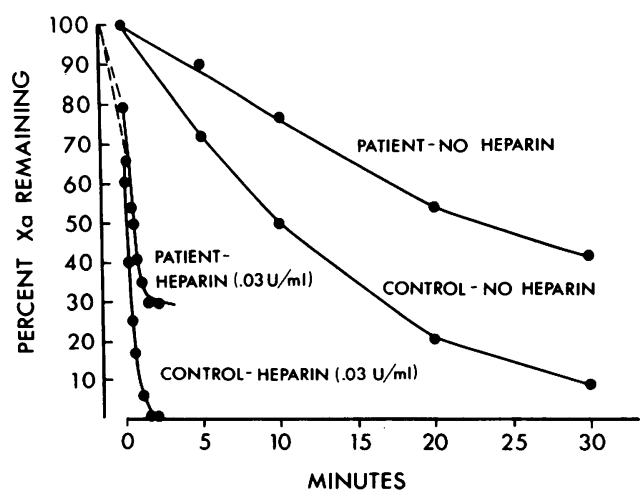

Figure 4. The neutralization (incubation of mixture at $37^{\circ} \mathrm{C}$ ) of $\mathrm{Xa}$ activity by purified preparations of AT-III in the presence and absence of heparin. Patient AT-III (AT-III "Denver" plus normal AT-III) shows a decreased rate of Xa neutralization as compared to control (all normal AT-III). 


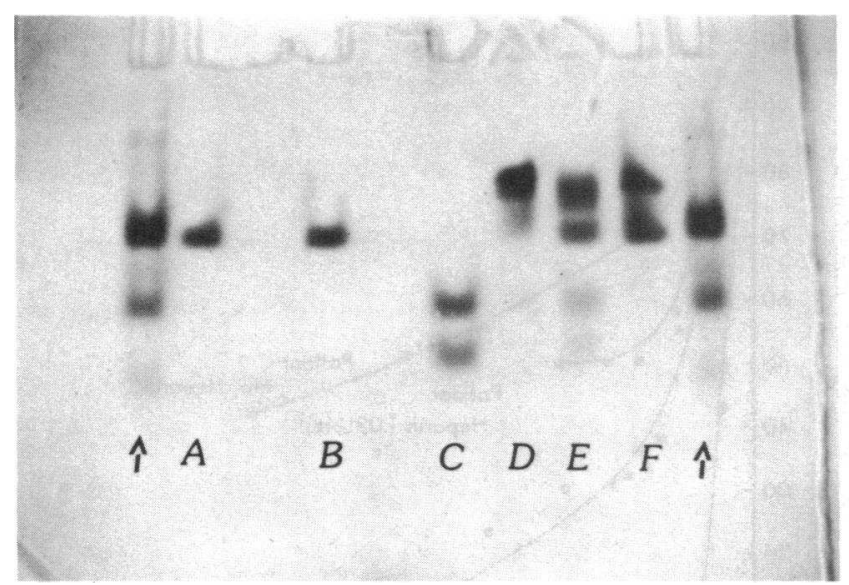

Figure 5. SDS-PAGE of TAT reaction mixtures. Lane $A$, purified control AT-III; lane $B$, purified patient AT-III; lane $C$, thrombin migrating as $\alpha$ and $\beta$ components; lane $D$, equimolar control AT-III + thrombin; lane $E$, equimolar patient AT-III + thrombin; lane $F$, two times molar concentration patient AT-III to thrombin; outside i lanes, reference proteins.

complexes. During the high salt $(0.6 \mathrm{~mol} \mathrm{NaCl})$ elution step, significant amounts of AT-III antigen-positive material were eluted for both patient and control. The control AT-III demonstrates heparin cofactor activity corresponding to the amount of antigen while the patient AT-III demonstrates no heparin cofactor activity. That this material eluted by $0.6 \mathrm{~mol} \mathrm{NaCl}, \mathrm{pH}$ 8.4, buffer represents primarily free AT-III was confirmed by SDS-PAGE (not shown).

${ }^{131}$ I-AT-III turnover studies. Studies on plasma samples of $\mathrm{AH} \mathrm{Jr}$ and AH showed that the plasma AT-III antigen and AT-

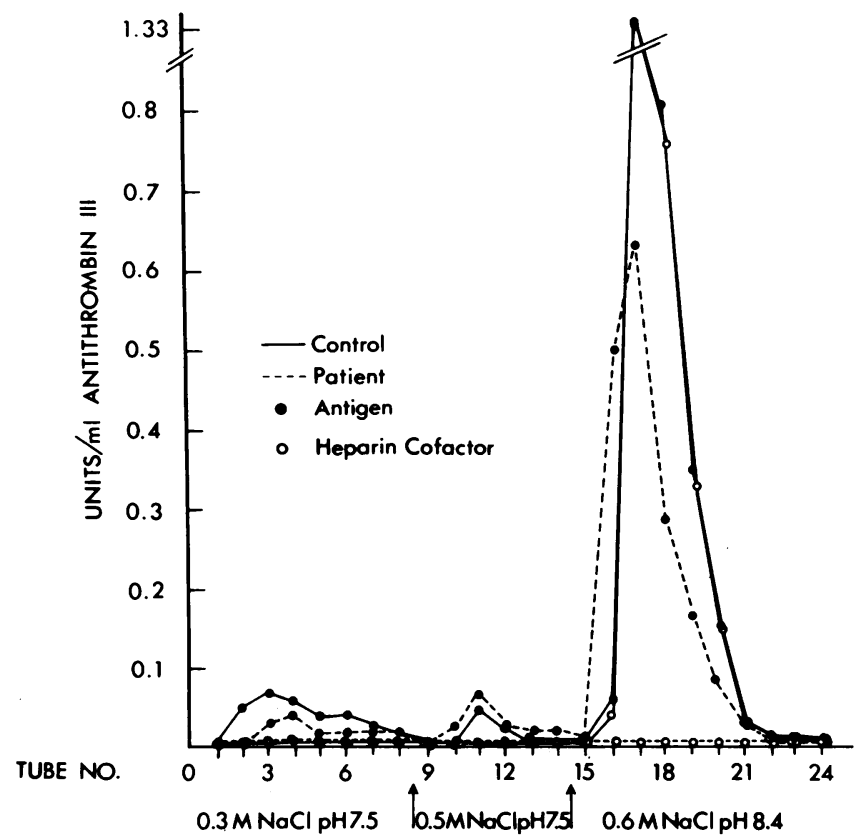

Figure 6. Elution profiles (from heparin-sepharose column) of TAT complex mixtures, prepared as detailed in Methods. Patient and control mixtures are measured for AT-III antigen and heparin cofactor activity for each aliquot collected over three elution steps.
III heparin cofactor levels (percent) were $100 / 50$ and $96 / 63$, respectively, while the proportionate levels in the chromatographically purified AT-III were $100 / 51$ and $96 / 62$. Therefore, both normal AT-III and variant AT-III have equal affinity for heparin and the proportions of the two AT-III's in the purified AT-III mixture are the same as those in the starting plasma.

Separate studies on AH Jr's chromatographed AT-III showed that $\mathrm{AT}$ and $\mathrm{AT}_{\mathrm{D}}$ were also labeled with ${ }^{125}$ I proportionately to their concentrations. After ${ }^{125} \mathrm{I}$ labeling the AT-III was reacted at $37^{\circ} \mathrm{C}$ with a slight excess of thrombin for $1 \mathrm{~h}$ and the free thrombin was inactivated with diphosphofluoridate. The mixture was absorbed to heparin agarose and washed well with buffer A, and then the TAT complexes were eluted with buffer C. $52 \%$ of the ${ }^{125}$ I was eluted and radioautographs of SDS-PAGE separations showed that $>93 \%$ of the eluted radioactivity ran with TAT complexes. The remainder of the radioactivity was then eluted with $0.01 \mathrm{~mol} / \mathrm{liter}$ Tris, $\mathrm{pH} 8.0,1.0 \mathrm{~mol} / \mathrm{liter} \mathrm{NaCl}$, and SDS-PAGE radioautographs showed $>93 \%$ of this was in the ${ }^{125} \mathrm{I}_{-} \mathrm{AT}_{\mathrm{D}}$ band. Before labeling, this AT-III preparation from AH Jr contained $50 \% \mathrm{AT}$ and $50 \% \mathrm{AT}_{\mathrm{D}}$.

Fig. 7 compares the turnover studies in $\mathrm{AH} \mathrm{Jr}$ (affected brother of the proband) with those in two male controls. In the studies in AH Jr both the normal and the variant AT-III were labeled. Minor differences between the $\mathrm{AH} \mathrm{Jr}$ and normal studies are: $(a)$ the slow slope of the AH Jr plasma curve falls a little faster; $(b)$ the $\mathrm{AH} \mathrm{Jr}$ whole-body curve after $2 \mathrm{~d}$ decreases more slowly; and (c) after $3 \mathrm{~d}$ the $\mathrm{AH} \mathrm{Jr}$ whole-body curve declines more slowly than his plasma curve. Because use of ${ }^{125}$ I-labeled purified AT-III "Denver" was not permissible (see later), the turnover parameters $D_{1} \mathrm{e}^{-d_{1} t}+D_{2} \mathrm{e}^{-d t t}$ of ${ }^{125} \mathrm{I}$-AT-III "Denver" (Table II) were obtained from the studies in AH Jr as described in the Appendix. Table II also gives mean values of the plasma parameters obtained in eight normal subjects and in AH Jr.

The normal and $D d$ parameters allow calculation of the fractional loss rates from the plasma, $j_{3}\left(\right.$ day $\left.^{-1}\right)$, of normal and variant ${ }^{125} \mathrm{I}$-AT-III using $j_{3}=\left(C_{1} / a_{1}+C_{2} / a_{2}\right)^{-1}$; see Appendix. In normals both alleles at the genetic locus make normal ATIII so that $j_{3}$ is an average rate. In $\mathrm{AH} \mathrm{Jr} j_{3}$ for normal ${ }^{125} \mathrm{I}-\mathrm{AT}$ -

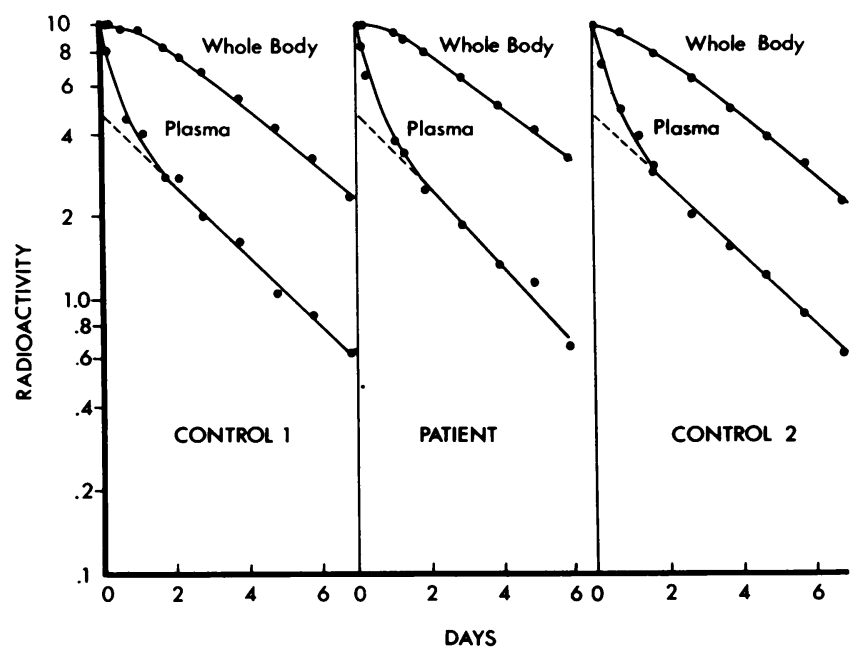

Figure 7. The course of turnover studies of autologous radiolabeled AT-III in affected family member AH Jr and two control males. Plasma and whole body radioactivity measurements are plotted reflecting decrements over time. Normal and variant species of AT-III from AH Jr labelled equally (see text). 
Table II. Turnover Data in Eight Normal Adults and Subject AH Jr

\begin{tabular}{|c|c|c|c|c|c|c|c|c|c|c|}
\hline Study & Species & $\begin{array}{l}\alpha \text { (fraction of } \\
\text { AT in plasma) }\end{array}$ & $C_{1}$ & $a_{1}$ & $C_{2}$ & $a_{2}$ & $\begin{array}{l}\text { AT-III plasma } \\
\text { concentration }\end{array}$ & Alleles & $j_{3}$ & $\begin{array}{l}\text { Synthesis/ } \\
\text { allele }\end{array}$ \\
\hline & & & & & & & $U / m l$ & & & $\%$ ml per day \\
\hline Controls $(\mathrm{Mm})$ & ${ }^{*} \mathrm{AT}$ & 1.0 & $\begin{array}{c}0.46 \\
(0.044)\end{array}$ & $\begin{array}{c}0.29 \\
(0.029)\end{array}$ & $\begin{array}{l}0.54 \\
(0.044)\end{array}$ & $\begin{array}{c}2.116 \\
(0.508)\end{array}$ & 1.0 & $2 \mathrm{~N}$ & $\begin{array}{c}0.54 \\
(0.055)\end{array}$ & 27 \\
\hline $\mathrm{AH} \mathrm{Jr}(H h)$ & ${ }^{*} \mathrm{AT},{ }^{*} \mathrm{ATD}$ & 0.59 & 0.467 & 0.317 & 0.533 & 2.196 & 0.94 & $1 \mathrm{~N}, 1 \mathrm{D}$ & $0.54,0.64$ & $29.7,25$ \\
\hline $\mathrm{AH} \mathrm{Jr}(D d)$ & ${ }^{*}$ ATD & 0 & 0.476 & 0.355 & 0.524 & 2.34 & 0.78 & $2 \mathrm{D}$ & 0.64 & 25 \\
\hline
\end{tabular}

See Appendix for definitions of abbreviations and terms.

III is taken as the mean of this rate and the fractional loss rate of plasma ${ }^{125} \mathrm{I}$-AT-III "Denver" is calculated on this assumption. These rates are given in Table II. Multiplying these by the appropriate plasma concentrations (percent per milliliter) gives the mass removal rates (percent per milliliter/day), which in the steady state equal the synthetic rates of the alleles (Table II).

\section{Discussion}

The affected family members in this report manifest a heritable AT-III deficiency disorder in which the gene controlling the production of a functionally variant AT-III molecule has been transmitted autosomally to the two affected siblings through the father. The coexistence in the three family members of both normal and abnormal AT-III molecules in approximately equal proportions accounts for the laboratory manifestations of a qualitative AT-III deficiency state, i.e., normal levels of AT-III antigen with a decrease in functional activity as measured in biologic assays. There is evidence that the defect in the variant molecule lies at the serine protease binding site, and that the heparin binding site is normal. CIE analysis of plasma samples reveals no unusual alteration of migration pattern occurring in the presence or absence of heparin in the agarose. Further, an intact AT-III-heparin interaction is suggested by an unremarkable elution profile of purified patient AT-III from the heparinsepharose affinity column. On the other hand, when the patient's serum is subjected to CIE analysis, there is a decrease of identifiable AT-III serine protease complexes, hence the presumed defective interaction between substrate and AT-III at its protease binding site.

A classification schema for congenital AT-III deficiency states has been suggested by Nagy and Losonczy (14). The type I disorder is a quantitative deficiency state characterized by decreased production of functionally intact AT-III molecules reflected in decreased AT-III antigen levels with a corresponding decrease in AT-III heparin cofactor and progressive antithrombin levels. Qualitative deficiency states (types II and III) are characterized by normal levels of AT-III antigen but diminished functional activity. In the type II deficiency state, the functional abnormality is demonstrable in both the progressive antithrombin and the heparin cofactor assays. In the type III disorder the functional defect is limited to the heparin cofactor assay with the progressive antithrombin activity being within normal limits. Current understanding of the nature of the AT-III molecules suggests that the variant molecules associated with classic type II deficiency states possess a functional abnormality at the serine protease binding site, and that classic type III variant molecules have an abnormal heparin-binding interaction.

Familial qualitative antithrombin deficiency states have also been classified by differences in progressive antithrombin deficiency, heparin cofactor activity, and heparin affinity (15). Using these measurements plus CIE patterns and anti-Xa activity, our family is different from most of the previously reported deficiencies. Abnormal anti-Xa activity distinguishes AT-III "Denver" from AT-III "Aalborg" $(16,17)$. The AT-III "Budapest" variant reveals an abnormal CIE pattern when heparin is present in the agarose (18). CIE of plasma samples without heparin in the agarose shows an abnormal pattern for AT-III "Milano" (19) and AT-III "Trento" (20). Interestingly, AT-III "Chicago" has an increased affinity for heparin-sepharose eluting at a higher salt concentration than normal AT-III (15). Based on currently available information it is not possible to distinguish AT-III "Hvidovre" (21) from our AT-III "Denver" variant. The ultimate differences between these protein variants will probably be found in the structural analysis of these proteins. Initial study indicates that the structural abnormality in AT-III "Denver" is a replacement of serine 394 (near the target arginine) by leucine (22).

In this report we employed a technique to separate normal from variant molecules present in our patient's plasma, thus taking advantage of the physical and chemical differences present at the protease binding of the variant molecules as well as the previously documented observation that AT-III serine protease complexes bind with reduced affinity to heparin (23). Starting with a solution of purified patient AT-III standardized to give $1.0 \mathrm{U} / \mathrm{ml}$ of antigen and $0.55 \mathrm{U} / \mathrm{ml}$ of heparin cofactor activity, addition of appropriate quantities of thrombin solution reduces the heparin cofactor activity to zero. Heparin-sepharose affinity chromatography of this mixture allows separation of the two AT-III species (free and complexed) from one another by virtue of differential binding to heparin. AT-III antigen-positive material is eluted from the column at all steps. At the 0.3 and 0.5 $\mathrm{M} \mathrm{NaCl}$ elution steps, there is evidence that the AT-III antigenpositive material is TAT complexes exclusively. This observation is based on tests demonstrating absent heparin cofactor activity (see Fig. 6), the lack of AT-III functional activity by progressive antithrombin and anti-Xa assays (data not shown), and the SDSPAGE of the eluates pooled from both steps demonstrating a slowly migrating band corresponding to the position of known TAT complexes. At the $0.6 \mathrm{M} \mathrm{NaCl}$ elution step, antigen-positive material is delivered from the column in substantial quantities. When tested separately, this free AT-III material lacked heparin cofactor, progressive antithrombin, and anti-Xa activity, migrated in a normal fashion on CIE with and without heparin, 
and failed to form TAT complexes when mixed again with thrombin solution. Hence the variant AT-III "Denver" molecule eluted at this step is immunologically identical with normal ATIII, binds normally to heparin, fails to bind to and neutralize its serine protease substrate, and thus demonstrates no measurable AT-III functional activity.

A question of much interest is whether the single amino acid substitution of leucine at serine 394 results in physiologic abnormalities other than failure to neutralize thrombin. Turnover studies with antithrombin III "Denver" can define its synthetic rate and several features of its catabolism. However, preparation of purified AT-III "Denver" requires removal of the normal AT-III as thrombin complexes before isolation of the AT-III "Denver." Because thrombin is prepared by activation of prothrombin with brain extracts, contamination of the ${ }^{125}$ I-AT-III "Denver" with virus contained in the thrombin preparation is possible. This led us to obtain the turnover of ${ }^{125}$ I-AT-III "Denver" from the turnover of the mixture of normal ${ }^{125} \mathrm{I}$-AT-III and ${ }^{125}$ I-AT-III "Denver" in AH Jr by correcting for the behavior of the normal ${ }^{125}$ I-AT-III. The latter was obtained from mean parameter values in studies on eight controls. This approach is mathematically correct and may prove useful in other studies; however, because only a single turnover study was made in $\mathrm{AH}$ $\mathrm{Jr}$ and because we cannot assume normal turnover in the body of a protein with an abnormal amino acid, we cannot assign a confidence value to the ${ }^{125}$ I-AT-III "Denver" parameters.

Turnover studies yield $j_{3}$, the fractional loss rate of ${ }^{125} \mathrm{I}$-ATIII from the plasma $\left(\right.$ day $\left.^{-1}\right)$, which when multiplied by the ATIII concentration (percent per milliliter) gives the mass loss rate percent per day per milliliter of plasma. Table II shows that in the control studies, the loss rate from the plasma averages 54\%/ $\mathrm{ml}$ of plasma per day. Table II also shows that the turnover study in $\mathrm{AH} \mathrm{Jr}$, representing the sum of normal and variant ${ }^{125} \mathrm{I}$ AT-III, gave a plasma loss rate of $54.5 \% / \mathrm{ml}$ of plasma per day, very close to the mean normal value. However, though the mean synthetic rate of AT-III "Denver" was normal, the fractional breakdown rate was increased to 0.64 per day (Table II).

In summary, AT-III "Denver" is a type II variant molecule with normal heparin interaction and abnormal serine protease binding characteristics. It is distinct from all but one of the reported type II variants. The technique outlined for the separation of the AT-III "Denver" variant molecule from its normal counterpart is applicable to other type II variant molecules allowing for the isolation of purified variant molecular species for separate testing and structural analysis.

\section{Appendix}

Determining turnover parameters of ${ }^{125} I-A T-I I I$ "Denver"

Obtaining the plasma curve. Terming normal ${ }^{125} \mathrm{I}-\mathrm{AT}$-III, *AT, and variant ${ }^{125} \mathrm{I}-\mathrm{AT}$-III, ${ }^{*} \mathrm{AT} \mathrm{T}_{\mathrm{D}}$, the plasma curve in $\mathrm{AH} \mathrm{Jr},{ }^{*} A \mathrm{~T}_{H}$, depends on the turnover and relative proportions of ${ }^{*} \mathrm{AT}$ and ${ }^{*} \mathrm{AT} \mathrm{T}_{\mathrm{D}} .{ }^{*} \mathrm{AT} \mathrm{T}_{\mathrm{H}}$ was determined from the turnover studies in $\mathrm{AH} \mathrm{Jr}$ and is described by $H_{1} \mathrm{e}^{-h_{1} t}+H_{2} \mathrm{e}^{-h_{2} t}$, where $H_{1}+H_{2}=1.0, H_{1}=0.467, H_{2}=0.533, h_{1}$ $=0.318, h_{2}=2.196$; see Table II. The mean parameters with standard deviations of the plasma curves in eight normal controls, *AT $=M_{1} \mathrm{e}^{-m_{1} t}+M_{2} \mathrm{e}^{-m 2 t}$, are also shown in Table II; $C_{1}, C_{2}, a_{1}$, and $a_{2}$ are constants obtained from curve analysis. The similarity of the parameters of ${ }^{*} A T_{H}$ and $* A T$ indicate that the plasma turnover of ${ }^{*} A T_{D}$, the variant ${ }^{125}$ I-AT-III, can be described quite well by a two-exponential curve, $D_{1} \mathrm{e}^{-d t}+D_{2} \mathrm{e}^{-d t}$, with $D_{1}+D_{2}=1.0$. With $\alpha$ as the fraction of *AT, and $1-\alpha$ as the fraction of ${ }^{*} \mathrm{AT}_{\mathrm{D}}$ in the ${ }^{125} \mathrm{I}-\mathrm{AT}$-III used for the turnover study in $\mathrm{AH} \mathrm{Jr}$, then:

${ }^{*} \mathrm{AT}_{\mathrm{H}}=\alpha \cdot{ }^{*} \mathrm{AT}+(1-\alpha) \cdot{ }^{*} \mathrm{AT} \mathrm{T}_{\mathrm{D}}$.

After substituting the parameters of ${ }^{*} A T$ and ${ }^{*} A T_{D}$ and rearranging, Eq. 1 becomes:

$$
\begin{aligned}
D_{1} \mathrm{e}^{-d_{1} t}+ & D_{2} \mathrm{e}^{-d_{2} t} \\
& =\left(H_{1} \mathrm{e}^{-h_{1} t}+H_{2} \mathrm{e}^{-h_{2} t}-\alpha \cdot\left(M_{1} \mathrm{e}^{-m_{1} t}+M_{2} \mathrm{e}^{-m_{2} t}\right)\right) /(1-\alpha) .
\end{aligned}
$$

All the parameters on the right-hand side are known so that the values of the left-hand side for the sampling times in the study on $\mathrm{AH} \mathrm{Jr}$ can be calculated. Using the relation in Eq. 2 values for $D_{1} \mathrm{e}^{-d_{1} t}+D_{2} \mathrm{e}^{-d t}$ were calculated for the $\mathrm{AH} \mathrm{Jr}$ sampling times and then best-fit values of $D_{1}, d_{1}, D_{2}$, and $d_{2}$ were obtained by computer program.

The fraction of normal AT-III in AH Jr's plasma was measured during the turnover study and was almost identical to the mean of four measurements made in 1983. Since, as noted above, this fraction was unchanged by heparin-agarose chromatography and by radioiodination, this fraction equals $\alpha$.

\section{Acknowledgments}

We express our appreciation to Ms. Norma Kure for the preparation of this manuscript.

This work was supported by U. S. Public Health Service Grant HL25477 and a grant from the Colorado Heart Association.

\section{References}

1. Rosenberg, R. D., and P. S. Damus. 1973. The purification and mechanism of action of human antithrombin-heparin cofactor. J. Biol. Chem. 248:6490-6505.

2. Abildgaard, U. 1979. A review of antithrombin III. In The Physiological Inhibitors of Coagulation and Fibrinolysis. D. Collen, B. Wiman, and W. Verstraete, editors. Elsevier, Amsterdam. 19-29.

3. Egeberg, O. 1965. Inherited antithrombin deficiency causing thrombophilia. Thromb. Diath. Haemorrh. 13:516-530.

4. Sas, G., G. Blasko, D. Banhegyi, J. Jako, and L. A. Palos. 1974. Abnormal antithrombin III (antithrombin III "Budapest") as a cause of a familial thrombophilia. Thromb. Diath. Haemorrh. 32:105-115.

5. Ambruso, D. R., L. J. Jacobson, and W. E. Hathaway. 1980. Inherited antithrombin III deficiency and cerebral thrombosis in a child. Pediatrics. 65:125-131.

6. Goodnight, S. H. Jr., J. L. Schaeffer, and K. Seth. 1980. Measurement of antithrombin III in normal and pathologic states using chromogenic substrate S-2238: comparison with immunoelectrophoretic and factor $\mathrm{Xa}$ inhibition assay. Am. J. Clin. Pathol. 73:639-647.

7. von Kaulla, E., and K. N. von Kaulla. 1967. Antithrombin III and diseases. Am. J. Clin. Pathol. 48:69-80.

8. Odegard, O. R., M. Lie, and U. Abildgaard. 1976. Antifactor Xa activity measured with amidolytic methods. Haemostasis. 5:265-275.

9. Andersson, L. O., L. Engman, and E. Henningsson. 1977. Crossed immunoelectrophoresis as applied to studies on complex formation. The binding of heparin to antithrombin III and the antithrombin III-thrombin complex. J. Immunol. Methods. 14:271-281.

10. Damus, P. S., and R. D. Rosenberg. 1976. Antithrombin-heparin cofactor. Methods Enzymol. 45:653-669.

11. Reeve, E. B., B. Leonard, S. H. Wentland, and P. Damus. 1980. Studies with ${ }^{131}$ I-labelled antithrombin III in dogs. Thromb. Res. 20: 375-389.

12. Weber, K., and M. Osborn. 1969. The reliability of molecular weight determinations by dodecyl sulfate-polyacrylamide gel electrophoresis. J. Biol. Chem. 244:4406-4412.

13. Ambruso, D. R., B. D. Leonard, R. D. Bies, L. Jacobson, W. E. 
Hathaway, and E. B. Reeve. 1982. Antithrombin III deficiency: decreased synthesis of a biochemically normal molecule. Blood. 60:78-83.

14. Nagy, I., and H. Losonczy. 1979. Three types of hereditary antithrombin III deficiency. Thromb. Haemostasis. 44:187. (Abstr.)

15. Bauer, K. A., J. B. Ashenhurst, J. Chediak, and R. D. Rosenberg. 1983. Antithrombin "Chicago": a functionally abnormal molecule with increased heparin affinity causing familial thrombophilia. Blood. 62:12421250.

16. Sorensen, P. J., J. Dyerberg, E. Stoffersen, and M. Kroghjensen. 1980. Familial functional antithrombin III deficiency. Scand. J. Hematol. 24:105-109.

17. Sorensen, P. J., G. Sas, I. Peto, G. Blasko, T. Kremmer, and A. Samu. 1982. Distinction of two pathologic antithrombin III molecules: antithrombin III "Aalborg" and antithrombin III "Budapest." Thromb. Res. 26:211-219.

18. Sas, G., D. S. Pepper, and J. D. Cash. 1975. Further investigations on antithrombin III in the plasmas of patients with the abnormality of antithrombin III "Budapest." Thromb. Diath. Haemorrh. 33:564-572.
19. Boyer, C., A. Tripodi, M. Wolf, P. M. Mannucci, and M. J. Larrieu. 1983. A new familial variant of antithrombin III: antithrombin III "Milano." Thromb. Haemostasis. 50:51. (Abstr.)

20. Girolami, A., F. Marafioti, M. Rubertelli, M. A. Vicarioto, G. Cappellato, and M. Mazzuccato. 1984. Antithrombin III Trento. A "new" congenital AT-III abnormality with a peculiar crossed immunoelectrophoretic pattern in the absence of heparin. Acta Haematol. 72:73-82.

21. Jorgensen, M., L. C. Petersen, and S. Thorsen. 1984. Purification and characterization of hereditary abnormal antithrombin III with impaired thrombin binding. J. Lab. Clin. Med. 104:245-256.

22. Stephens, A. W., B. S. Thalley, and C. H. W. Hirs. 1985. Antithrombin III Denver, a ser to leu ${ }^{394}$ variant without protease inhibitory activity. Thromb. Haemostasis. 54:49. (Abstr.)

23. Carlstrom, A. S., K. Lieden, and I. Bjork. 1977. Decreased binding of heparin to antithrombin following the interaction between antithrombin and thrombin. Thromb. Res. 11:785-797. 